\title{
ANÁLISE DE DISCURSO AMBIENTAL E CIENTÍFICO NO RECURSO DIDÁTICO "PROTOCOLO PARA AVALIAÇÃO DA SAÚDE DE RIOS E LAGOAS", UTILIZADO EM PROJETOS DE EDUCAÇÃO AMBIENTAL EM MINAS GERAIS, BRASIL: REFLEXÕES A PARTIR DO ENFOQUE CTSA ${ }^{1}$
}

\author{
Guilherme Trópia ${ }^{2}$ \\ Flávia Elizabeth de Castro Viana ${ }^{3}$ \\ Artur Queiroz Guimarães ${ }^{4}$
}

Resumo: Neste trabalho, analisamos os discursos referentes à Educação Ambiental (EA) em um recurso didático chamado "Protocolo para avaliação da saúde de rios e lagoas". Apresentamos o projeto Pampulha Limpa, que utilizou o recurso didático analisado em suas atividades com crianças em fase de escolarização básica. Assumimos uma perspectiva integradora do enfoque Ciência, Tecnologia e Sociedade (CTSA) com a EA para analisar os sentidos atribuídos à EA no recurso didático. A partir das discussões do enfoque CTSA, apontamos como as relações da atividade científica com as questões ambientais se constituem e se essa produção científica contempla discussões que associam aspectos entre a ciência e a sociedade. Os resultados apontam discursos referentes à EA exclusivamente associados à atividade científica, afastados das relações e implicações com a sociedade. Apontamos o enfoque CTSA como uma possibilidade de articular a atividade científica com outras áreas do saber, permitindo uma visão mais ampla dos conhecimentos científicos diante das questões ambientais.

Palavras-chave: Recurso didático. CTSA. Análise do discurso.

\section{ENVIRONMENTAL AND SCIENTIFIC DISCOURSE ANALYSIS OF AN EDUCATIONAL RESOURCE CALLED "PROTOCOL FOR THE ASSESSMENT OF THE HEALTH OF RIVERS AND LAGOONS”, USED IN ENVIRONMENTAL EDUCATION PROJECTS IN MINAS GERAIS, BRAZIL: REFLECTIONS BASED ON THE STSE APPROACH}

Abstract: In this work, we analyze the discourses about Environmental Education (EE) present in an educational resource called "Protocol for the assessment of the health of rivers and lagoons". We present the Clean Pampulha project, which used the aforementioned educational resource with elementary school children. Adopting a perspective that integrates STSE and EE, we analyze the meanings assigned to EE in the educational resource. Based on the STSE approach, we point out the relationships between scientific activity and environmental issues and if that scientific production contemplates discussions involving both science and society. The results show that discourses related to EE are exclusively associated with scientific activity, away from the relationships and implications with the society. We indicate the STSE approach as a possible way to integrate scientific activity with other areas of knowledge, allowing for an enlarged vision of scientific knowledge with respect to environmental issues.

\footnotetext{
${ }^{1}$ Uma versão inicial do trabalho foi apresentada no V EPEA.

2 Professor do Departamento de Educação da Universidade Federal de Juiz de Fora(UFJF), Mestre em Educação Científica e Tecnológica pela Universidade Federal de Santa Catarina (UFSC), Juiz de Fora, Brasil, guilherme.tropia@ufjf.edu.br

${ }^{3}$ Orientadora Acadêmica de Biologia - MEC/CAPES.Sistema Universidade Aberta do Brasil, Polo UAB Muaná (PA), Mestre em Ecologia, Conservação e Manejo da Vida Silvestre pela Universidade Federal de Minas Gerais (UFMG), Brasil, flaviabeth1@gmail.com

${ }^{4}$ Professor da Rede Estadual de Minas Gerais. Licenciado em Ciências Biológicas pela Universidade Federal de Minas Gerais (UFMG), Brasil, arturqueiroz@hotmail.com
} 
Keywords: Educational resource. STSE. Discourse analysis.

\section{ANÁLISIS DE DISCURSO AMBIENTAL Y CIENTÍFICO EN EL RECURSO DIDÁCTICO “PROTOCOLO PARA EVALUACIÓN DE LA SALUD DE RÍOS Y LAGUNAS”, UTILIZADO EN PROYECTOS DE EDUCACIÓN AMBIENTAL EN MINAS GERAIS, BRASIL: REFLEXIONES A PARTIR DEL ENFOQUE CTSA}

Resumen: En este trabajo, analizamos los discursos referentes a la Educación Ambiental (EA) en un recurso didáctico llamado "Protocolo para evaluación de la salud de ríos y lagunas". Presentamos el proyecto Pampulha Limpa, que utilizó el recurso didáctico analizado en sus actividades con niños en fase de escolarización básica. Asumimos una perspectiva integradora del enfoque Ciencia, Tecnología y Sociedad (CTSA) con la EA para analizar los sentidos atribuidos a la EA en el recurso didáctico. A partir de las discusiones del enfoque CTSA, apuntamos como las relaciones de actividad científica con cuestiones ambientales se constituyen y si esa producción científica contempla discusiones que asocian aspectos entre la ciencia y la sociedad. Los resultados apuntan discursos referentes a la EA exclusivamente asociados a la actividad científica, distantes de las relaciones e implicaciones con la sociedad. Apuntamos el enfoque CTSA como una posibilidad de articular la actividad científica con otras áreas del saber, permitiendo una visión más amplia de los conocimientos científicos frente a las cuestiones ambientales.

Palabras clave: Recurso didáctico. CTSA. Análisis del discurso.

\section{Introdução}

A trajetória dos estudos e práticas educativas em Educação Ambiental (EA) no Brasil tem sido marcada em grande parte por perspectivas que possibilitam a difusão da problemática ambiental e promoção de práticas de caráter conservacionista ou naturalista. Essas perspectivas assumem a divulgação e reflexão de conhecimentos sobre o cuidado e melhor aproveitamento dos recursos naturais através de atividades que promovem padrões de comportamentos que preservam o meio natural onde as sociedades se desenvolvem. No entanto, como apontam Kawasaki e Carvalho (2009), perspectivas em EA diferentes das concepções naturalistas ou conservacionistas ganham espaço nos estudos tanto em ambiente escolar como fora dele.

Nesse contexto, os meios de comunicação em massa e os sistemas de educação formal e não formal têm papel importante na formação de cidadãos que refletem sobre os problemas ambientais a partir de diferentes enfoques. Na educação formal brasileira, a EA é um dos componentes do cotidiano escolar, sendo o meio ambiente instituído como tema transversal através da proposição dos Parâmetros Curriculares Nacionais (BRASIL, 1997). Entretanto, pesquisas (BIZZERIL; FARIA, 2003; CASTILLO, 1999) evidenciaram que poucos pesquisadores envolvidos com a problemática ambiental produzem materiais educativos para a população leiga e em especial para crianças em escolarização básica.

Neste ensaio, analisamos o discurso ambiental e científico referente à EA em um recurso didático ${ }^{5}$ utilizado no projeto Pampulha Limpa. Estivemos envolvidos na elaboração e aplicação desse material de 2003 a $2006^{6}$. Para realizar as discussões do estudo, nos baseamos na articulação

\footnotetext{
${ }^{5}$ Esse recurso didático foi apresentado no V Encontro Ibero-Americano de Educação Ambiental (Joinville, SC, 2006) e reformulado para publicação na revista Ciências Hoje das Crianças (volume 208, 2009).

${ }^{6}$ Esse recurso didático modificado foi utilizado nas atividades de EA em outros projetos, como o Manuelzão (www.manuelzao.ufmg.br), que é um projeto de extensão da Faculdade de Medicina da UFMG e tem como principal objetivo a revitalização da Bacia do Rio das Velhas, maior afluente em extensão do Rio São Francisco. Também foi utilizado nos projetos educacionais da empresa de turismo pedagógico Estação Terra (www.estacaoterra.com), que 
de referenciais teóricos e metodológicos da análise do discurso de linha francesa (AD) a partir de autores como Orlandi (2003) e Pêcheux (1993) e das reflexões do enfoque CTSA (Ciência, Tecnologia, Sociedade e Ambiente). A articulação desses referenciais tem sido denominada por pesquisadores da educação científica e tecnológica educação CTS (Ciência, Tecnologia e Sociedade) em perspectiva discursiva (CASSIANI; VON LINSINGEN, 2009; VON LINSINGEN; CASSIANI, 2010). Pretendemos evidenciar possíveis incompletudes do discurso sobre EA no recurso didático não a fim de desvalorizá-lo, mas de evidenciar possibilidades para trabalhar e discutir as questões ambientais em projetos de EA a partir dele.

\section{Educação Ambiental, projeto Pampulha Limpa e recursos didáticos}

Educação Ambiental em ambientes urbanos é uma abordagem de vanguarda em discussão ampla na sociedade (BUCK; MARIN, 2005; DIAS, 2003; VIEIRA; OLIVEIRA, 2011), pois se acredita que a aprendizagem em um processo de EA seja mais efetiva quando está inserida na realidade de seus participantes. Esse tipo de abordagem promove o entendimento dos cidadãos em relação à cidade e aos seus problemas ambientais (DIAS, 2003) e faz com que as pessoas entendam que a ordem social em que vivem é criada por elas próprias, seja pela ação ou pela omissão (TORO; WERNECK, 1997).

Baseando-se nesses princípios, foi organizado o projeto Pampulha Limpa (PL). Esse projeto de Educação Ambiental iniciou-se em 2003 e foi criado por iniciativa própria de alunos e pesquisadores do Instituto de Ciências Biológicas da Universidade Federal de Minas Gerais (ICB/UFMG) preocupados com a problemática ambiental no entorno da Bacia Hidrográfica da Lagoa da Pampulha. O PL caracterizou-se como atividade de extensão da UFMG e teve o apoio de várias instituições, como o Consórcio de Recuperação da Bacia da Pampulha e a Prefeitura de Belo Horizonte.

A Lagoa da Pampulha se destaca por seu acervo cultural e arquitetônico, importância turística e histórica e por abrigar grande diversidade de animais, representando uma oportunidade para a população entrar em contato com a natureza, cada vez mais difícil nos grandes centros urbanos. O local representa um dos principais cartões postais da cidade de Belo Horizonte, capital do estado de Minas Gerais. Apesar dessa importância, a Lagoa tem sido alvo de uma crescente degradação, resultante de três vetores principais: assoreamento, eutrofização antrópica e aporte de lixo. Este último fator está intimamente associado à questão de educação ambiental, na qual o projeto PL atuou.

O PL visou à sensibilização, conscientização e mobilização da população quanto aos problemas, ambientais e sociais, gerados pelo lixo na Lagoa da Pampulha. Uma de suas formas de atuação era o "Dia Mundial de Limpeza de Rios e Praias", idealizado pela ONG "The Ocean Conservancy "7", que incentiva a coleta anual de resíduos sólidos em mais de 120 países. As atividades do PL eram realizadas, majoritariamente, com estudantes de escolas de educação básica - nível fundamental. Todas as escolas que participaram do projeto se localizavam na Bacia Hidrográfica da Pampulha.

Entre as diversas atividades educativas desenvolvidas pelo PL estava a realização de saídas de campo para locais que apresentavam condições ambientais distintas, de modo a permitir comparações. Alguns locais visitados com os estudantes foram: Lagoa da Pampulha, Parque das Mangabeiras e Serra do Cipó.

presta assessoria em EA para escolas de ensino infantil, fundamental e médio na região metropolitana de Belo Horizonte.

7 The Ocean Conservancy é a mais antiga organização dedicada à proteção dos mares. Com mais de 900 mil membros e voluntários, essa ONG combina advocacia baseada em ciência, ativismo local e educação, para achar soluções duráveis para tópicos que afetam os mares e toda a vida marinha. As limpezas de praias tiveram seu começo no estado do Texas (EUA) em 1986, por um membro da Ocean Conservancy chamada Linda Maraniss. Já em 1989, as limpezas foram reconhecidas internacionalmente, sendo chamado de "International Coastal Cleanup" ou "Dia Mundial de Limpeza de Praias". Atualmente, esse evento vem crescendo a cada ano devido à inclusão, recentemente, de campanhas de limpeza em rios, lagoas e nascentes. www.oceanconservancy.org 
Com a finalidade de auxiliar a observação, sensibilização e apropriação de conceitos referentes à EA pelos alunos durante atividades do PL, os organizadores do projeto adaptaram o protocolo proposto por Callisto et al. (2002), usado por limnólogos para avaliar o nível de preservação das condições ecológicas de trechos de bacias hidrográficas, de modo a permitir a avaliação rápida da diversidade de habitats em atividades de EA para crianças. O recurso didático utilizado no PL chama-se "Protocolo para avaliação da saúde de rios e lagoas - modificado para jovens cientistas" e foi utilizado com estudantes durante saídas de campo do projeto Pampulha Limpa.

Educadores ambientais ressaltam que a produção de material didático que divulgue conhecimentos sobre meio ambiente, de linguagem acessível, mas sem se afastar do rigor científico, é importante para auxiliar professores e alunos em ensino e aprendizagem de ciências (BIZERRIL; FARIA, 2003). Pesquisas sobre o estado da arte têm apontado os recursos didáticos em EA como um foco temático frequente na produção acadêmica em EA no Brasil (LORENZETTI; DELIZOICOV, 2006; MEGID NETO, 1998).

\section{O enfoque CTSA}

A crença atribuída à ciência, principalmente pela matematização e formalização dos seus mecanismos de linguagem através do método científico, constituiu uma concepção de ciência neutra e universal no século XX. Essa crença atribuída à ciência criou a expectativa de que o desenvolvimento científico e tecnológico poderia, de certo modo, colocar fim às angústias e males da humanidade e com isso se esperava que um estado de bem-estar social tomasse conta da vida do cidadão comum. Havia uma associação direta entre o desenvolvimento científico e um crescente bem-estar social. O modelo de desenvolvimento em que mais ciência e mais tecnologia geraria mais riqueza e bem-estar social para os países era um dos pressupostos que impulsionavam os investimentos na produção científica (MORAES, 2008).

No entanto, essa provável segurança construída sobre o terreno científico, criada através de uma imensa contingência de invenções, começou a dar sinais de desgaste no período pósSegunda Guerra Mundial. Vestígios de resíduos contaminantes, envenenamentos farmacêuticos, derramamento de petróleo, acidentes nucleares, entre outros, ajudaram a dissolver o mito de um desenvolvimento científico-tecnológico alinhado ao benefício da população (BAZZO; VON LISINGEN; PEREIRA, 2003), pois, apesar das benesses inegáveis da produção científica, o custo de tudo isso era lamentável e perceptível aos olhos do público leigo em geral.

Assim, começa um questionamento crítico sobre o papel da ciência e da tecnologia na sociedade. Não que a tecnologia e a ciência sejam as únicas, ou tenham total responsabilidade pelos males da humanidade. Porém, seus efeitos podem ser prejudiciais no decorrer dos anos, num primeiro momento imperceptíveis aos olhos de quem faz seu uso, pois o discurso tecnológico geralmente nos mostra tecnologia como sinônimo de: aprimoramento e modernidade, inteligência e promessa de futuro, humanização e novidade (COMMASSETTO, 2004).

Em meados de 1960 e começo de 1970 tem início o movimento CTS (ciência, tecnologia e sociedade), que buscava questionar a cultura tecnológica imposta pelas novas descobertas científicas no período pós-Segunda Guerra e, principalmente, indagar os efeitos nocivos decorrentes dessa época. Várias discussões contribuíram para a formação do movimento CTS: (a) o movimento ambiental que explicitava e denunciava o agravamento dos problemas ambientais em decorrência das novas descobertas científicas e tecnológicas (um marco importante desse movimento foi a publicação do livro "Primavera Silenciosa", de Rachel Carson, em 1962); (b) as discussões sobre a natureza do conhecimento científico, entre as quais destacamos a publicação da "Estrutura das Revoluções Científicas", de Thomas Kuhn, também em 1962, que privilegiava

\footnotetext{
${ }^{8} \mathrm{O}$ recurso didático se encontra integralmente no anexo deste trabalho.
} 
aspectos históricos e sociológicos na análise da produção científica, evidenciando que o conhecimento científico não se institui de forma linear e cumulativa, baseado apenas em aspectos lógico-empiristas.

Assim, o movimento CTS buscou não somente compreender o produto das interações entre o social, a ciência e a tecnologia mas contemplar o porquê e como surgiram. Nessa perspectiva, a ciência passa a ser vista como algo cultural, dinâmico, submetido às mais diversas esferas, sejam elas políticas, éticas, sociais ou econômicas, contrapondo-se à concepção neutra do Positivismo.

Essa concepção evidenciou-se principalmente pela realização de políticas públicas intervencionistas para tentar regular e controlar a tecnologia vigente e até mesmo deixá-la mais transparente ao público em geral.

A velha política do laissez-faire proposta para a ciência começa a se transformar em uma política mais intervencionista, onde os poderes públicos desenvolvem e aplicam uma série de instrumentos técnicos, administrativos e legislativos para encaminhar o desenvolvimento científico e tecnológico e supervisionar seus efeitos sobre a natureza e a sociedade. (BAZZO; VON LINSINGEN; PEREIRA, 2003, p. 123).

No campo das discussões em educação, o enfoque CTS foi apropriado a partir da década de 1980 e, de acordo com Invernizzi e Fraga (2007), foi no processo de adaptação das pesquisas em CTS para o ensino de ciências que a sigla aumentou uma letra, o "A" (de CTSA) referente ao ambiente. Apesar de não negar que o enfoque CTS já contemplava a questão ambiental, o enfoque CTSA "vem resgatar o papel da educação ambiental (EA) do movimento inicial de CTS" (SANTOS, 2007, p. 1) e corresponde à "importância crescente que a dimensão sócio-ambiental [sic] vinha conquistando no sistema de ensino através da Educação Ambiental" (INVERNIZZI; FRAGA, 2007, p. 2). Desse modo, o enfoque CTSA no contexto educativo sugere

[...] que a ciência e a tecnologia sejam assumidas como referências dos saberes escolares e a sociedade e o ambiente sejam tratados como o cenário de aprendizagem, do qual os problemas e questões sociais significativas surgiram como temas a serem investigados com o suporte dos saberes científicos e tecnológicos. (RICARDO, 2007, p. 2).

Assim, balizados por trabalhos que apontam associações integradoras entre CTSA e EA (COMPIANI, 2007; FARIAS; FREITAS, 2007; LOUREIRO; LIMA, 2009), assumimos o enfoque CTSA para analisar os discursos referentes à educação ambiental no recurso didático "Protocolo para avaliação da saúde de rios e lagoas", utilizado em projetos de educação ambiental, como o Pampulha Limpa. Essa análise se deu numa perspectiva discursiva a partir de articulações com os estudos da análise do discurso francesa, os quais apresentamos na próxima seção.

\section{Análise do discurso de linha francesa (AD)}

O movimento de levar, através de recursos didáticos para crianças, conhecimentos sobre EA passa por uma reformulação na forma de expor os conceitos e fenômenos relacionados ao meio ambiente. No entanto, de acordo com os referenciais da $\mathrm{AD}$, essa reformulação não se dá apenas na estruturação da linguagem nos materiais didáticos de EA. Para a AD, a formulação e o funcionamento de um texto não se restringem ao enunciado no sentido empírico, mas devem ser consideradas as condições de produção de sentidos, que englobam o sujeito, o texto, o contexto histórico-social. Segundo Orlandi (2003, p. 15-16),

[...] a Análise de Discurso não trabalha com a língua enquanto um sistema abstrato, mas com a língua no mundo, com maneiras de significar, com homens 
falando, considerando a produção de sentidos enquanto parte de suas vidas, seja enquanto sujeitos, seja enquanto membros de uma determinada forma de sociedade.

A AD considera que a linguagem não é transparente e que o seu funcionamento não trata apenas de transmissão de informação. A $\mathrm{AD}$ vai além da literalidade do texto, compreendendo a linguagem como efeito de sentidos da interação dos seres em sociedade e de processos históricos. Nesse contexto, insere-se a definição de discurso como efeito de sentidos entre interlocutores. Os efeitos de sentidos estão ligados a vários fatores: as posições ocupadas pelos interlocutores, o lugar de onde falam, as formações discursivas ${ }^{9}$ em que estão inseridos, a imagem que têm de si e dos outros, o que é dito e o que não é dito, em geral, todas as condições que abrangem a produção de um discurso. Pêcheux (1993, p. 82) discute: “O que funciona nos processos discursivos é uma série de formações imaginárias que designam o lugar que A e B se atribuem cada um a si e ao outro, a imagem que eles fazem de seu próprio lugar e do outro".

De acordo com Orlandi (2003, p. 40), não são "os sujeito físicos ou lugares empíricos que funcionam no discurso, mas sim suas formações imaginárias". A autora dá três exemplos de formações imaginárias: as relações de força (posições sociais dos interlocutores), as relações de sentidos (relação de um discurso com os outros) e o mecanismo de antecipação (o sujeito diz de um modo de acordo com o efeito que imagina produzir em seu interlocutor).

Outro dispositivo analítico e teórico da $\mathrm{AD}$ se refere àquilo que não é dito. O silêncio é parte do discurso, pois, no momento em que se diz alguma coisa, outra é silenciada. Para Orlandi (2003, p. 85), “o que não é dito, o que é silenciado constitui igualmente o sentido do que é dito”. Assim, os sentidos, no discurso sobre EA, não estão determinados pela língua, mas pelas relações que os sujeitos estabelecem, tanto ao dizerem quanto ao não dizerem.

Assim, analisamos o discurso científico e ambiental no material didático sob estudo a partir dos dispositivos analíticos da $\mathrm{AD}$ descritos anteriormente: (a) as formações imaginárias relações de sentido e de força - no discurso ambiental e no científico, como se instituem as relações da atividade científica com as questões ambientais e se essa produção científica contempla discussões que associam aspectos entre a ciência e a sociedade; (b) a formação discursiva dos autores do protocolo; (c) os diferentes efeitos de sentidos sobre o que é EA pelo que é dito e pelo que é silenciado.

\section{Análise do "Protocolo para avaliação da saúde de rios e lagoas"}

A partir das reflexões teóricas do enfoque CTSA, da AD e das discussões sobre a EA, passamos a analisar o discurso referente à EA no "Protocolo para avaliação da saúde de rios e lagoas". Pretendemos identificar os indícios do processo de significação que se situam no tex to e entender através dos mecanismos de funcionamento do discurso como o texto produz sentidos sobre EA.

O recurso didático analisado consiste em quatro partes: instruções, protocolo, quadro e interpretação da pontuação e glossário. A primeira parte, referente às instruções, sinaliza aos estudantes como utilizar o material didático: formar grupos, completar o quadro de pontuação, verificar a interpretação, utilizar o glossário (se necessário) e discutir com o professor/monitor.

O primeiro aspecto que levantamos para discutir nessa parte é referente ao discurso veiculado sobre a ciência no material didático de EA. Selecionamos dois trechos retirados das instruções do recurso didático: "Vocês agora são cientistas que devem avaliar a saúde de rios e

\footnotetext{
${ }^{9}$ A formação discursiva é "aquilo que numa formação ideológica dada - ou seja, a partir de uma posição dada em uma conjuntura sócio-histórica dada - determina o que pode e deve ser dito” (ORLANDI, 2003, p. 43).
} 
lagoas. Por onde vocês começam?" e "Este protocolo é utilizado pelos mais famosos pesquisadores em todo o mundo, e agora será utilizado também por vocês". Esses trechos remetem a uma visão fascinante da ciência em que os estudantes, ao assumirem a posição do cientista, já que utilizarão o mesmo instrumento que "os mais famosos cientistas do mundo", poderão avaliar de forma objetiva a saúde de rios e lagoas. Percebemos aí uma crença da atividade científica de forma acrítica, que é parte do imaginário ideológico disseminado em nossa sociedade, vinculada à visão da atividade científica como possibilitadora da determinação do real, do verdadeiro.

Nas instruções também percebemos uma valorização da atividade científica em relação às atividades de EA. Estudos como Farias e Freitas (2007) apontam um reducionismo ao olharemse as questões ambientais apenas pela atividade científica. Aprofundaremos essa discussão adiante.

A segunda parte do recurso didático apresenta o protocolo que possibilita aos alunos coletar os dados para a avaliação da saúde do ambiente analisado. O protocolo consiste em doze perguntas relacionadas a fatores que caracterizam os locais visitados, como diversidade de habitats, animais e plantas aquáticas, mata ciliar, transparência e cheiro da água, composição do fundo do rio/lagoa, assoreamento, erosão e existência de esgoto e lixo. Cada pergunta possui três alternativas de resposta ( $a, b$ e c).

Evidenciamos que a maioria das perguntas do protocolo privilegia aspectos relacionados às ciências da natureza, focando a avaliação do ambiente pelo conhecimento da realidade natural. De acordo com Almeida (2007), a associação entre as ciências da natureza e a EA tem sido criticada por ser considerada uma visão redutora da EA, marcada apenas por abordagem naturalista e conservacionista, uma concepção de EA frequente nas décadas de 1960 e $1970 . \mathrm{Na}$ Conferência de Tbilisi, em 1977, as discussões apontavam que a EA não deveria se restringir a tratar dos aspectos biológicos e físicos dos problemas ambientais, deveria abordar também as causas econômicas, sociais e culturais a eles relacionadas, ressaltando-se a correlação existente entre esses aspectos.

Ressaltamos que essa abordagem naturalista, que privilegia os aspectos das ciências da natureza, é importante para as atividades de EA. "O apelo sensitivo do contacto com a natureza continua a fazer todo o sentido, até porque uma EA centrada na resolução de problemas não é isenta de crítica" (ALMEIDA, 2007, p. 530). No entanto, essa abordagem constitui um problema quando as questões ambientais são tratadas apenas por esse enfoque, o que é presente no discurso sobre EA do protocolo sob estudo.

As condições de produção do recurso didático nos apontam processos de significação que privilegiam a abordagem naturalista. A formação discursiva dos autores do recurso didático remete a concepções ideológicas da EA voltada para as ciências da natureza, já que os autores eram estudantes e/ou pesquisadores da área de ciências biológicas, ligados ao ICB/UFMG. Assim, os sentidos da EA no protocolo se filiam em grande parte às questões das ciências da natureza, o que pode remeter a visões equivocadas da EA.

$\mathrm{Na}$ terceira parte do recurso didático está o quadro e a interpretação da pontuação obtida na coleta dos dados pelas respostas dos estudantes ao protocolo. Cada resposta dada no protocolo corresponde a uma pontuação no quadro: resposta "a" tem valor de 8 pontos, resposta "b" vale 4 e resposta "c" vale zero. O estudante deve somar todos os pontos que correspondem às suas respostas e interpretar a pontuação de acordo com o estabelecido: acima de 64 pontos o ambiente é natural, entre 40 e 64 pontos o ambiente é alterado e abaixo de 40 pontos o ambiente é impactado. Com base nesse resultado, o estudante avalia o ambiente sob estudo.

Analisamos que o recurso didático tem perspectiva instrumentalista e pouco reflexiva. Os alunos coletam os dados através das repostas objetivas, somam os pontos e associam essa pontuação a uma interpretação que já está dada. O recurso didático privilegia a coleta dos dados empíricos, mas não leva os alunos à reflexão das condições socioambientais que os levaram a classificar o ambiente de acordo com determinada resposta, o que remete a uma concepção neutra, afastada da sociedade, que se insere nas questões ambientais. 
Nessa discussão, apontamos ainda que, por enfatizar os alunos como pequenos cientistas, o recurso didático proporciona aos alunos uma concepção da produção científica neutra e objetiva, amplamente criticada pelos estudos da educação CTSA, e associa as questões ambientais exclusivamente a discursos equivocados da produção científica.

Nesse caso, entendemos que o recurso didático remete a sentidos da ciência como algo dado, ou melhor, toma a educação científica desenvolvida não como construção, mas como resultado de dados empíricos. Nesse sentido, quando pensamos nas relações de força, podemos inferir que, ao tomarem contato com esse tipo de linguagem, os alunos são levados a se posicionar como reprodutores das "instruções científicas", em vista do poder de autoridade conferido ao discurso científico.

Farias e Freitas (2007) apontam que a associação entre EA e a produção e educação científica tende a situar-se no contexto educativo das ciências da natureza, no qual a EA é lida predominantemente a partir apenas da produção científica. Essa associação é importante pelo fato de que os conhecimentos científicos são imprescindíveis para uma compreensão das questões ambientais. Os professores das disciplinas das ciências da natureza são os que mais se mobilizam em projetos de EA, o que é evidente na participação dos professores das escolas que são contempladas no projeto Pampulha Limpa.

Porém, como já referido, a EA com o olhar apenas dos conhecimentos científicos tem sido analisada com uma perspectiva reduzida, em que somente pela ciência onipotente se solucionariam as questões ambientais. De acordo com Almeida (2007), o conhecimento científico tem potencial para articular-se com outras áreas do saber, o que tem sido evidenciado nas tendências didáticas das ciências, como o enfoque educacional CTSA.

Tanto a abordagem CTSA quanto a EA enfatizam uma preocupação em que a educação deve formar cidadãos capazes de tomar decisões sobre problemas atuais. Entendemos que o discurso científico pode contribuir para essa formação, desde que não silencie a dimensão da produção científica como um aspecto social, diferentemente da perspectiva assumida no recurso didático analisado. O enfoque educacional CTSA assume essa perspectiva tomando a ciência e a tecnologia como instituições que possuem relações e implicações com diversas esferas da sociedade, como os aspectos políticos e econômicos. Assim, assume a produção científica como um aspecto social, diferentemente da perspectiva assumida no recurso didático analisado. A abordagem CTSA visa uma compreensão do mundo na sua globalidade e complexidade, o que contribuiria para a elaboração de materiais didáticos utilizados em projetos de EA com uma visão mais ampla dos conhecimentos científicos diante das questões ambientais.

A última parte do recurso didático apresenta um glossário com definições de conceitos utilizados no protocolo. Em caso de dúvida sobre o conceito, os alunos poderiam consultar o glossário. Assim, como o discurso no protocolo sobre EA remete a uma abordagem naturalista, as definições do glossário de palavras como "monocultura" e "mata ciliar" também enfatizam apenas explicações relacionadas às ciências da natureza.

\section{Considerações Finais}

Buscamos, neste trabalho, discutir sobre os discursos relativos à EA em um recurso didático utilizado no projeto Pampulha Limpa, do qual fomos colaboradores entre os anos de 2003 a 2006. Para a análise, recorremos ao enfoque CTSA em uma perspectiva discursiva, entendendo que essa abordagem possibilita a discussão do funcionamento de discursos que constituem a EA no material analisado.

Os resultados apontam que no discurso do recurso didático há uma centralidade na atividade científica que é colocada de forma acrítica, baseada somente na coleta empírica dos dados e na classificação de uma interpretação que já está definida pelo material. Discutimos que a abordagem ambiental no recurso didático situa-se predominantemente em aspectos naturalísticos relacionados às ciências da natureza, o que remete à própria formação discursiva dos autores do 
recurso didático, que são estudiosos das ciências biológicas. Consideramos a abordagem naturalista importante para projetos de EA, principalmente com crianças, mas problemática quando apropriada de forma excessivamente privilegiada em relação a outras abordagens de EA, o que evidenciamos no recurso didático analisado.

Assinalamos também que há uma exclusividade em discutir as questões ambientais a partir de uma atividade científica no recurso didático, perspectiva que tem sido apontada por estudos como reducionista pelo fato de a EA contemplar dimensões além dos conhecimentos científicos. No entanto, discutimos que os conhecimentos científicos têm possibilidades de dialogar com outras áreas do saber, o que é evidenciado pelas propostas educacionais baseadas no enfoque CTSA. Apontamos que a perspectiva CTSA pode trazer contribuições significativas ao discurso referente à EA no recurso didático, já que tanto o enfoque CTSA quanto a EA propõem discussões dos conhecimentos científicos e das questões ambientais a partir dos enfoques político, econômico, científico, cultural, entre outros, a fim de formar cidadãos críticos diante da complexidade do mundo em que vivemos.

As discussões apresentadas neste trabalho podem ajudar os educadores ambientais a repensar os recursos didáticos utilizados em atividades de EA. Perante a incompletude de muitos desses recursos, o educador ambiental pode e deve buscar maneiras de suprir essas limitações discursivas e assim ampliar os significados das atividades realizadas. O protocolo analisado neste trabalho apresenta contribuições para a EA, sobretudo ao auxiliar na orientação do olhar do estudante do ensino fundamental, que na maioria das vezes é disperso. Porém, é insuficiente se usado enquanto única ferramenta didática.

Ressaltamos também que algumas das incompletudes evidenciadas na análise do recurso didático destinado ao público do ensino fundamental resultam do próprio processo de formulação e funcionamento do discurso para torná-lo mais acessível e atraente a esse público. Não queremos dizer com isso que essas incompletudes, que são constituintes do discurso, estão naturalizadas no processo educativo, mas que é preciso atenção e senso crítico por parte dos educadores na produção de sentidos dos educandos ao avaliarem e adotarem esses recursos.

\section{Referências}

ALMEIDA, António. Que papel para as Ciências da Natureza em Educação Ambiental? Discussão de idéias a partir de resultados de uma investigação. Revista Electrónica de Enseñanza de las Ciencias, v. 6, n. 3, p. 522-537, 2007.

BAZZO, Walter; VON LINSINGEN, Irlan; PEREIRA, Luis Teixeira do Vale (Ed.). Introdução aos Estudos CTS (Ciência, Tecnologia e Sociedade). Madrid: Organização dos Estados IberoAmericanos para a Educação, a Ciência e a Cultura (OEI), 2003.

BIZERRIL, Marcelo Ximenes Aguiar; FARIA, Dóris S. A escola e a conservação do Cerrado: uma análise no ensino fundamental do Distrito Federal. Revista Eletrônica do Mestrado em Educação Ambiental, v. 10, n. 1, p. 19-31, 2003.

BRASIL. Parâmetros Curriculares Nacionais: meio ambiente e saúde. Brasília: Secretaria de Educação Fundamental, 1997.

BUCK, Sonia; MARIN, Andreia Aparecida. Educação para pensar questões socioambientais e qualidade de vida. Educar em Revista, n. 25, p. 197-212, 2005.

CALLISTO, Marcos; FERREIRA, Wander Ribeiro; MORENO, Pablo; GOULART, Michael Dave; PETRUCIO, Mauricio Mello. Aplicação de um protocolo de avaliação rápida da diversidade de habitats em atividades de ensino e pesquisa (MG-RJ). Acta Limnol. Bras., v. 14, n. 1, p. $91-98,2002$. 
CASSIANI, Suzani; VON LINSINGEN, Irlan. Formação inicial de professores de Ciências: perspectiva discursiva na educação CTS. Educar em Revista, n. 34, p. 127-147, 2009.

CASTILLO, Alicia. La educación ambiental y las instituciones de investigación ecológica: hacia una ciencia com responsabilidad social. Tópicos en educación ambiental, México, v. 1, n. 1, p. 35-46, 1999.

COMASSETTO, Leandro Ramires. A Celebração tecnológica no discurso do cotidiano. Publicatio UEPG - Ciências Humanas, Ciências Sociais Aplicadas, Lingüística, Letras e Artes, Ponta Grossa, v. 12, n. 1, p. 67-74, jun. 2004.

COMPIANI, Mauricio. O lugar e as escalas e suas dimensões horizontal e vertical nos trabalhos práticos: implicações para o ensino de ciências e educação ambiental. Ciência \& Educação, v. 13, n. 1, p. 29-45, 2007.

DIAS, Genebaldo Freire. Educação Ambiental: princípios e práticas. 8. ed. São Paulo: Gaia, 2003.

FARIAS, Carmen Roselaine de Oliveira; FREITAS, Denise de. Educação Ambiental e relações CTS: uma perspectiva integradora. Ciência \& Ensino, v. 1, n. especial, nov. 2007.

INVERNIZZI, Noela; FRAGA, Laís. Estado da arte na educação em ciência, tecnologia e sociedade e ambiente no Brasil. Ciência \& Ensino, v. 1, n. especial, 2007.

LORENZETTI, Leonir; DELIZOICOV, Demétrio. Educação Ambiental: um olhar sobre dissertações e teses. Revista Brasileira de Pesquisa em Educação em Ciências, v. 6, n. 2, 2006.

LOUREIRO, Carlos Frederico Bernardo; LIMA, Jacqueline Girão Soares de. Educação Ambiental e Educação Científica na perspectiva Ciência, Tecnologia e Sociedade (CTS): pilares para uma educação crítica. Acta Scientiae, v. 11, n. 1, p. 88-100, 2009.

KAWASAKI, Clarice Sumi; CARVALHO, Luiz Marcelo de. Tendências da Pesquisa em Educação Ambiental. Educação em Revista, v. 25, n. 3, p. 143-157, 2009.

MEGID NETO, Jorge. O ensino de ciências no Brasil: catálogo analítico de teses e dissertações (1972-1995). Campinas: Unicamp/CEDOC, 1998.

MORAES, Gustavo Henrique. Educação tecnológica, formação bumanista: uma experiência CTS no CEFET-SC. Dissertação (Mestrado em Educação Científica e Tecnológica) - Universidade Federal de Santa Catarina, Florianópolis, 2008.

ORLANDI, Eni. Análise do Discurso: Princípios e Procedimentos. 5. ed. Campinas: Pontes, 2003.

PÊCHEUX, Michel. Análise Automática do Discurso (1969). In: GADET, Françoise; HAK, Tony (Org.). Por uma análise automática do discurso: Uma introdução à obra de Michel Pêcheux. Campinas: Pontes, 1993.

RICARDO, Elio Carlos. Educação CTSA: obstáculos e possibilidades para sua implementação no contexto escolar. Ciência \& Ensino, v. 1, n. especial, p. 1-12, 2007.

SANTOS, Wildson Luiz Pereira dos. Contextualização no ensino de ciências por meio de temas CTS em uma perspectiva crítica. Ciência \& Ensino, v. 1, n. especial, 2007. 
TORO, José Bernardo; WERNECK, Nisia Maria Duarte. Mobilização Social: um modo de construir a democracia e a participação. Brasília: Ministério da Justiça, 1997.

VIEIRA, Ana Carolina Pires; OLIVEIRA, Silmara Sartoreto de. Educação Ambiental e Saúde Pública: uma análise crítica da literatura. Ambiente \& Educação, v. 16, n. 1, p. 37-44, 2011.

VON LINSIGEN, Irlan; CASSIANI, Suzani. Educação CTS em perspectiva discursiva: contribuições dos Estudos Sociais da Ciência e da Tecnologia. Redes, v. 16, n. 31, p. 163-182, 2010 .

\section{Anexo}

\section{Protocolo para avaliação da saúde de rios e lagoas - modificado para crianças cientistas}

\section{Instruções:}

Vocês agora são cientistas que devem avaliar a saúde de rios e lagoas. Por onde vocês começam?

Este protocolo é utilizado pelos mais famosos pesquisadores em todo o mundo, e agora será utilizado também por vocês.

Formem grupos de 3 ou 4 pessoas. Cada grupo deverá ler atentamente as perguntas, discuti-las e escolher uma única resposta (a, b, ou c).

Após responderem as perguntas, completem o quadro de pontuação e interpretem os resultados obtidos. Como está a saúde do lugar estudado?

Se houver qualquer dúvida com relação a alguma palavra com asterisco $(*)$, consulte o glossário.

Quando terminarem a atividade, discutam cada pergunta com o professor, o monitor ou outro responsável.

Mão a obra!

\begin{tabular}{|c|c|c|c|}
\hline Perguntas & \multicolumn{3}{|c|}{ Respostas } \\
\hline $\begin{array}{l}\text { 1. O que existe em } \\
\text { maior quantidade em } \\
\text { volta do rio/lagoa? }\end{array}$ & (a) Vegetação natural & $\begin{array}{l}\text { (b) Plantações, criação } \\
\text { de animais, capim ou } \\
\text { grama, monocultura* }\end{array}$ & $\begin{array}{l}\text { (c) Casas, lojas ou } \\
\text { indústrias }\end{array}$ \\
\hline $\begin{array}{l}\text { 2. Como é a mata } \\
\text { ciliar*? }\end{array}$ & $\begin{array}{l}\text { (a) Existem muitas } \\
\text { plantas de espécies } \\
\text { diferentes }\end{array}$ & $\begin{array}{l}\text { (b) Existem poucas } \\
\text { plantas de espécies } \\
\text { diferentes }\end{array}$ & $\begin{array}{l}\text { (c) Quase não há } \\
\text { plantas }\end{array}$ \\
\hline $\begin{array}{l}\text { 3. Existe erosão* nas } \\
\text { margens? }\end{array}$ & (a) Não & (b) Pouca & (c) Muita \\
\hline $\begin{array}{l}\text { 4. Existe } \\
\text { assoreamento*? }\end{array}$ & (a) Não & $\begin{array}{l}\text { (b) Pouco, alterando } \\
\text { apenas a composição } \\
\text { do fundo do rio/lagoa }\end{array}$ & $\begin{array}{l}\text { (c) Muito, chegando a } \\
\text { diminuir o espelho } \\
\text { d'água }\end{array}$ \\
\hline $\begin{array}{l}\text { 5. Existe lixo na } \\
\text { margem? }\end{array}$ & (a) Não & (b) Pouco & (c) Muito \\
\hline $\begin{array}{l}\text { 6. Existe esgoto? } \\
\text { (observar se existem } \\
\text { canos ou tubos } \\
\text { desembocando no } \\
\text { rio/lagoa) }\end{array}$ & (a) Não & (b) Pouco & (c) Muito \\
\hline $\begin{array}{l}\text { 7. Como é a } \\
\text { transparência da água? }\end{array}$ & (a) A água é clara & $\begin{array}{l}\text { (b) A água é um pouco } \\
\text { escura }\end{array}$ & $\begin{array}{l}\text { (c) A água é muito } \\
\text { escura (turva) }\end{array}$ \\
\hline 8. A água tem cheiro? & (a) Não & (b) O cheiro é fraco & (c) O cheiro é forte \\
\hline $\begin{array}{l}\text { 9. Como é a } \\
\text { diversidade de habitats* } \\
\text { dentro do rio/lagoa } \\
\text { para os organismos } \\
\text { aquáticos? }\end{array}$ & $\begin{array}{l}\text { (a) Muito diversificado } \\
\text { (pedras de vários } \\
\text { tamanhos, troncos de } \\
\text { árvores, plantas } \\
\text { aquáticas, folhas, etc.) }\end{array}$ & $\begin{array}{l}\text { (b) Mais ou menos } \\
\text { diversificado }\end{array}$ & $\begin{array}{l}\text { (c) Pouco diversificado } \\
\text { (apenas } 1 \text { ou } 2 \text { tipos } \\
\text { diferentes de habitats) }\end{array}$ \\
\hline $\begin{array}{l}\text { 10. Como é a } \\
\text { diversidade de animais* } \\
\text { (aquáticos e terrestres)? }\end{array}$ & $\begin{array}{l}\text { (a) Existem várias } \\
\text { espécies de animais } \\
\text { diferentes }\end{array}$ & $\begin{array}{l}\text { (b) Existem poucas } \\
\text { espécies de animais } \\
\text { diferentes }\end{array}$ & $\begin{array}{l}\text { (c) Quase não há } \\
\text { animais ou há muitos } \\
\text { organismos de uma }\end{array}$ \\
\hline
\end{tabular}




\begin{tabular}{|l|l|l|l|}
\hline & & & mesma espécie \\
\hline $\begin{array}{l}\text { 11. Como é a } \\
\text { diversidade de plantas } \\
\text { aquáticas? }\end{array}$ & $\begin{array}{l}\text { (a) Existem vários } \\
\text { tipos de plantas } \\
\text { aquáticas }\end{array}$ & $\begin{array}{l}\text { (b) Existem poucas } \\
\text { plantas aquáticas }\end{array}$ & $\begin{array}{l}\text { (c) Não existem } \\
\text { plantas aquáticas ou } \\
\text { existem grandes } \\
\text { quantidades de um } \\
\text { único tipo (p. ex. } \\
\text { aguapé) }\end{array}$ \\
\hline $\begin{array}{l}\text { 12. Existem } \\
\text { ações/projetos sendo } \\
\text { realizados que } \\
\text { contribuem para a } \\
\text { qualidade do rio/lagoa? }\end{array}$ & $\begin{array}{l}\text { (a) Há ações/projetos } \\
\text { e eles são eficazes }\end{array}$ & $\begin{array}{l}\text { (b) Há ações/projetos, } \\
\text { mas não estão sendo } \\
\text { eficazes }\end{array}$ & $\begin{array}{l}\text { (c) Não há } \\
\text { ações/projetos em } \\
\text { realização }\end{array}$ \\
\hline
\end{tabular}

Quadro de pontuação:

\begin{tabular}{|c|c|c|c|}
\hline Letra marcada & Valor & $\begin{array}{c}\text { Número de letras } \\
\text { marcadas }\end{array}$ & Total de pontos \\
\hline (a) & 8 pontos & & \\
\hline (b) & 4 pontos & & \\
\hline (c) & 0 pontos & & \\
\hline TOTAL & --- & -- & \\
\hline
\end{tabular}

\section{Interpretação da pontuação:}

Mais de 64 pontos: Ambiente Natural

Entre 40 e 64 pontos: Ambiente Alterado

Menos de 40 pontos: Ambiente Impactado

\section{Glossário:}

- Monocultura: Plantação de uma única espécie vegetal.

- Mata Ciliar: Vegetação que fica em volta do rio ou lagoa.

- Erosão: Desgaste do solo devido à chuva, vento ou outros fenômenos naturais. Observar a quantidade de solo sem cobertura vegetal.

- Assoreamento: Grande acúmulo de terra ou areia no fundo do rio/lagoa.

- Diversidade de habitats: Número de ambientes naturais diferentes que possuem características favoráveis para a sobrevivência e desenvolvimento das espécies que ali vivem.

- Diversidade de animais ou plantas: Número de espécies diferentes.

Observação: As águas, antes de serem bebidas, devem ser cuidadosamente tratadas, mesmo em se tratando de ambientes considerados naturais.

Artigo recebido em 05/08/2011

Artigo aprovado em 09/02/2012 